\title{
Glacial flour dust storms in the Gulf of Alaska: Hydrologic and meteorological controls and their importance as a source of bioavailable iron
}

\author{
John Crusius, ${ }^{1}$ Andrew W. Schroth, ${ }^{1}$ Santiago Gassó, ${ }^{2}$ Christopher M. Moy, ${ }^{1,3}$ \\ Robert C. Levy, ${ }^{4}$ and Myrna Gatica ${ }^{5}$ \\ Received 22 December 2010; revised 2 February 2011; accepted 7 February 2011; published 18 March 2011.
}

[1] Iron is an essential micronutrient that limits primary productivity in much of the ocean, including the Gulf of Alaska (GoA). However, the processes that transport iron to the ocean surface are poorly quantified. We combine satellite and meteorological data to provide the first description of widespread dust transport from coastal Alaska into the GoA. Dust is frequently transported from glacially-derived sediment at the mouths of several rivers, the most prominent of which is the Copper River. These dust events occur most frequently in autumn, when coastal river levels are low and riverbed sediments are exposed. The dust plumes are transported several hundred kilometers beyond the continental shelf into iron-limited waters. We estimate the mass of dust transported from the Copper River valley during one 2006 dust event to be between 2580 ktons. Based on conservative estimates, this equates to a soluble iron loading of 30-200 tons. We suggest the soluble Fe flux from dust originating in glaciofluvial sediment deposits from the entire GoA coastline is two to three times larger, and is comparable to the annual $\mathrm{Fe}$ flux to GoA surface waters from eddies of coastal origin. Given that glaciers are retreating in the coastal GoA region and in other locations, it is important to examine whether fluxes of dust are increasing from glacierized landscapes to the ocean, and to assess the impact of associated $\mathrm{Fe}$ on marine ecosystems. Citation: Crusius, J., A. W. Schroth, S. Gassó, C. M. Moy, R. C. Levy, and M. Gatica (2011), Glacial flour dust storms in the Gulf of Alaska: Hydrologic and meteorological controls and their importance as a source of bioavailable iron, Geophys. Res. Lett., 38, L06602, doi:10.1029/ 2010 GL046573.

\section{Introduction}

[2] Iron $(\mathrm{Fe})$ is an essential micronutrient that limits primary productivity in large regions of the ocean. Iron limitation of phytoplankton in the Gulf of Alaska (GoA) has long been suspected from elevated concentrations of nitrate that are present year-round [Conkright et al., 1994] and was

\footnotetext{
${ }^{1}$ Woods Hole Coastal and Marine Science Center, U.S. Geological Survey, Woods Hole, Massachusetts, USA.

${ }^{2}$ Goddard Earth Sciences and Technology Center, University of Maryland Baltimore County, Baltimore, Maryland, USA.

${ }^{3}$ Geology Department, University of Otago, Dunedin, New Zealand.

${ }^{4}$ Science Systems and Applications, Inc., Lanham, Maryland, USA.

${ }^{5}$ School of Earth and Environmental Sciences, Queens College, City University of New York, Flushing, New York, USA.
}

Copyright 2011 by the American Geophysical Union. 0094-8276/11/2010GL046573 confirmed by Fe fertilization experiments [Boyd et al., 2004]. In the northern GoA, the few existing Fe data are consistent with limited transport beyond coastal waters, as near-surface concentrations decrease rapidly beyond the continental shelf [Wu et al., 2009; Lippiatt et al., 2010]. However, research is needed to understand the relative importance of Fe supply from dust, volcanic ash, biomass burning, upwelling, currents and eddies of coastal origin.

[3] Dust is thought to be one of the important sources of Fe to the GoA, but as with most regions, there are few measurements [see Mahowald et al., 2009]. Here we describe a potentially important but largely undocumented source of dust and $\mathrm{Fe}$ to the GoA, glacial flour-rich riverbed sediments of coastal Alaska. The GoA coastline is lined by large mountains, and $29 \%$ of the surface area of the GoA watershed is covered by glaciers [Wang et al., 2004]. Hence, considerable glacial flour is formed and transported to the coast in rivers. In this work we use meteorological and remote sensing datasets to examine source regions of dust, the hydrologic and meteorological controls on dust plume formation, the scales of transport, and the seasonality of dust inputs into the GoA. In addition, we characterize the dust mineralogy and solid-phase $\mathrm{Fe}$ speciation to constrain $\mathrm{Fe}$ solubility. Finally, we estimate the amount of dust and soluble Fe transported to GoA surface waters during a prominent event, and compare this to Fe flux estimates from eddies originating in coastal waters.

\section{Methods}

[4] Methods are described in the auxiliary material. ${ }^{1}$

\section{Results and Discussion}

[5] Large dust plumes are visible emanating from the coastal GoA region in MODIS true-color images from 2003, 2005, 2006, 2008, 2009 and 2010. These events commonly occurred between late October and mid November and frequently resulted in dust transport several hundred kilometers beyond the continental shelf (Figure 1). Dust events ranged in duration from a few days to two weeks and multiple events were observed in some years. These duration and frequency estimates should be viewed as minima because of the lack of MODIS data retrievals under cloudy conditions (see auxiliary material). The most prominent dust plumes appear to emanate from the valley of the Copper River, the largest source of fresh water to the GoA [Wang

\footnotetext{
${ }^{1}$ Auxiliary materials are available in the HTML. doi:10.1029/ 2010GL046573.
} 

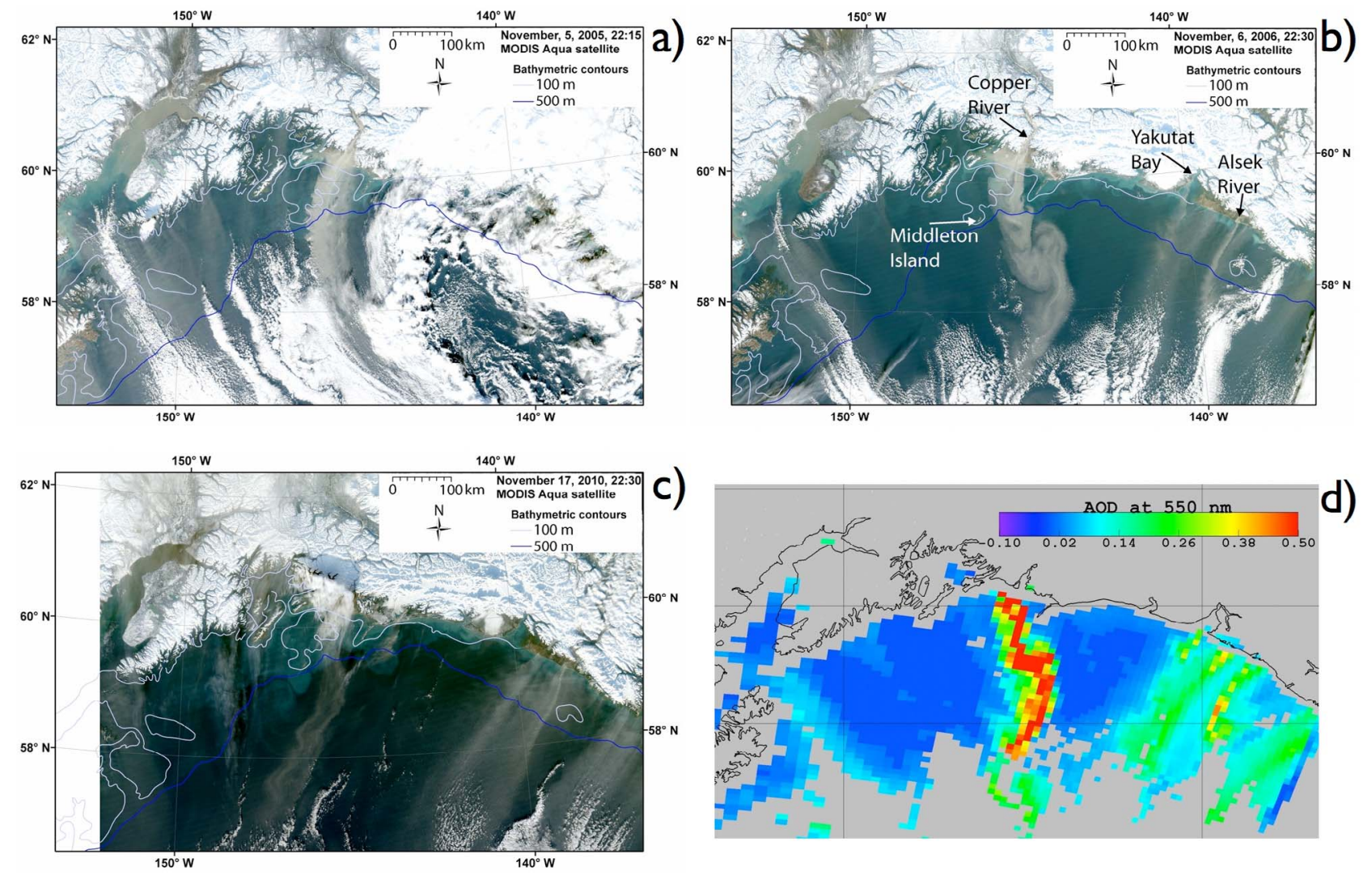

Figure 1. True-color images derived from MODIS data of dust emanating from riverbed sediments of coastal Alaska. Also shown on each image is the $100-\mathrm{m}$ bathymetric contour (white line) and the 500-m contour (blue line); (a) November 5, 2005; (b) November 6, 2006. Arrows point to locations mentioned in text; (c) November 17, 2010; (d) aerosol optical thickness (AOT) inferred for November 6, 2006. True-color images were made using hdflook (http://www-loa.univ-lille1.fr/ Hdflook/hdflook_gb.html).

et al., 2004]. However, in 2006 and 2010, dust originated also from the Alsek River and Yakutat Bay (Figures $1 \mathrm{~b}$ and 1c).

\subsection{Source and Seasonality of Dust Events}

[6] The dust plumes seem to come from geomorphologically similar locations along the Alaskan coast, and at similar times, which allows us to infer much about processes that generate the dust. The dust emanates from river valleys that drain glacierized catchments (e.g., the Copper River, the Alsek River) or from termini of piedmont glaciers (e.g., Yakutat Bay, adjacent to the Malaspina glacier) (Figures 1a1d). A common attribute of all these localities is that glacial erosion results in large quantities of fine-grained sediment (glacial flour) being transported and deposited near the coast. Most of the dust events we have identified occurred in the autumn. We propose that dust events occur in this season in part because extensive regions of river-derived sediment are exposed when river discharge is at an annual minimum (Figure 2). Indeed, the Copper River stage height is typically several meters lower in autumn than at its peak [Brabets, 1997]. Events in March 2003 (Figure S1) and January 2011 (not shown) demonstrate, however, that events can also occur in late winter, when river levels are also low. The hydrology of the source area is thus an important control. However, in winter the potential dust source areas tend to be blanketed by snow (Figure 2). Satellite imagery and our own observations indicate that the Copper River delta is a region of substantial snow accumulation and the ground surface typically remains covered with snow through at least March. During summer the dust source areas are largely submerged because the Copper River discharge peaks in July and August (Figure 2).

[7] Meteorological data help further explain these dust events. While not the dominant wind direction, surface northerly winds are necessary to transport significant dust into the GoA. Winds recorded on Middleton Island $\left(59.432^{\circ} \mathrm{N}\right.$ $146.338^{\circ} \mathrm{W}$; Figure 1b), $100 \mathrm{~km} \mathrm{SW}$ of the Copper River delta and at the edge of the continental shelf, are not strongly affected by local topography (maximum elevation $\sim 50 \mathrm{~m}$ ), and should be representative of winds extending into $\mathrm{Fe}$ limited waters. Ten years of hourly wind measurements (Figure 3b) reveal windflow primarily along the east-west axis. However, measurements during a significant dust event are entirely from the northeast (Figure 3c), directly from the Copper River delta (also see Figure S6). Reanalysis data, from the National Centers for Environmental Prediction (NCEP) [Kalnay et al., 1996], show that the northerly winds are driven by large-scale synoptic conditions, specifically a high-pressure anomaly in the Bering Sea and low pressure in the northern Pacific Ocean (Figure 3a). The Middleton Island data reveal that winds from the NNE are rare in the 


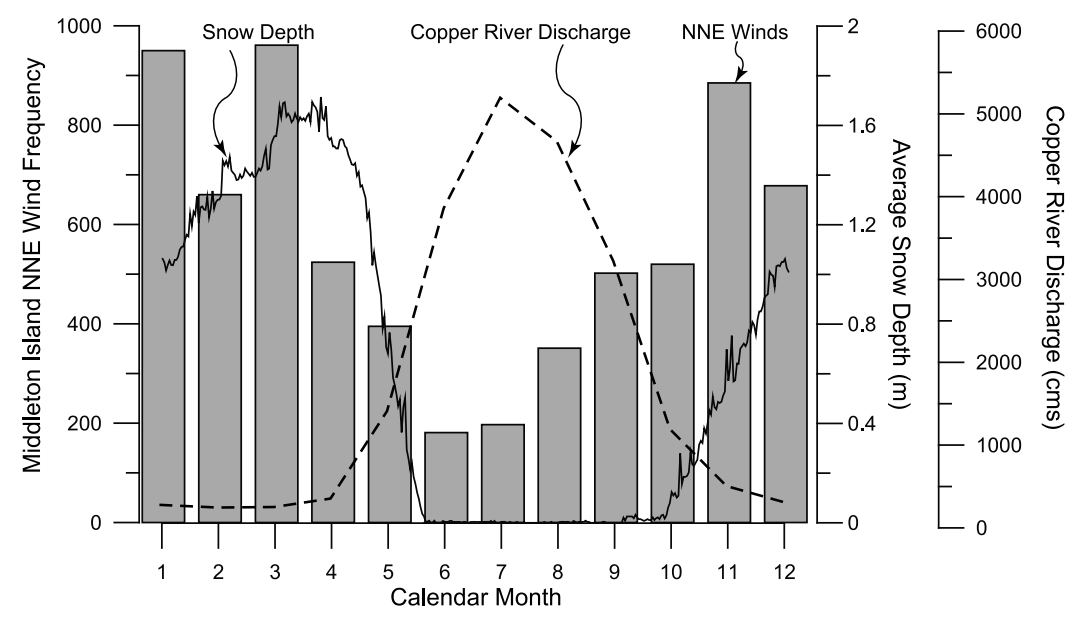

Figure 2. Monthly frequency distribution of hourly wind measurements originating from the NNE (0-50 degrees) on Middleton Island from 2000-2009 (see Figure 1b). Superimposed are monthly average Copper River discharge [Brabets, 1997] and average snow depth (2004-2010) in the upper Copper River watershed (Upper Tsaina River; 520 meters above sea level). See auxiliary material.

summer and spring, and more common in the winter and autumn (Figure 2). Strong winds (e.g., $>11 \mathrm{~m} \mathrm{~s}^{-1}$ ) are also more common during winter and autumn. Thus, the GoA dust events are most common in autumn, coinciding with both a maximum in river sediment exposure and favorable wind directions.

\subsection{Dust Mineralogy and Fe Speciation}

[8] The impact of these dust events on the ocean depends, among other things, on how much dust is deposited and how much of the iron in the dust is available to phytoplankton. Recent work has suggested that the solubility of $\mathrm{Fe}$ in aerosols may be strongly influenced by the Fe speciation (bonding environment and oxidation state [Schroth et al., 2009]) and mineralogy [Journet et al., 2008] of dust. X-ray diffraction data indicate the dominant minerals present in the dust are plagioclase and quartz, while the Fe-bearing phases are clay minerals, amphiboles, and magnetite (see Table S1). Indeed, iron-specific synchrotron-based X-ray absorption spectroscopic data confirm that $\mathrm{Fe}$ is present primarily in mixed valence silicate phases $(74 \%)$, with roughly half of the $\mathrm{Fe}$ in the ferrous (reduced) form. This is consistent with Fe sourced in bedrock only recently exposed to surficial weathering and is typical of glacial flour, wherein there has been limited time for diagenetic alteration of the primary mineral forms of Fe (Table S1). Furthermore, the presence of $\mathrm{Fe}$ in these mineral phases suggests a relatively high $\mathrm{Fe}$ solubility, as recent work demonstrates that $\mathrm{Fe}$ in clay minerals can be more soluble than crystalline iron (hydr) oxides [Journet et al., 2008], and that Fe(II)-bearing silicates are an important source of soluble $\mathrm{Fe}$ in some mineral dust [Cwiertny et al., 2008].

\subsection{Estimate of Dust and Soluble Iron Deposition on the GoA}

[9] The most complete and cloudless view of a dust plume by MODIS occurred on November 6th, 2006 (Figure 1b), from which we estimated aerosol optical thickness (AOT) [Remer et al., 2005]. The algorithm used to infer AOT did not originally detect these autumn, high-latitude events because of the steep angle of view. On the basis of these images (Figure 1), however, the algorithm was modified, and the resulting map of AOT shows dust plumes emanating from several locations along the GoA coast (Figure 1d). A near-simultaneous observation of the vertical structure of this dust cloud by the CALIPSO satellite confirmed that most of the dust was located in the lower $1200 \mathrm{~m}$ of the atmosphere, with no dust above cloud level.

[10] We made the best possible estimate of dust deposition, given the available information (see auxiliary material). We assume most of the dust is eventually deposited somewhere over the GoA by both precipitation and dry deposition, given that most of the dust is in the boundary layer. We estimated the mass of dust in the November 6, 2006 image using three approaches. In the first, we estimated the aerosol mass per unit area (parameter Mass_Concentration Ocean_Best) derived by the MODIS aerosol algorithm [Remer et al., 2005]. The concentrations within the plume averaged $30 \mu \mathrm{g} \mathrm{cm}^{-2}$. Integrated over the entire plume, we estimate the total mass to have been 9 ktons $\left(9.0 \times 10^{9} \mathrm{~g}\right)$. The second method is based on the observed proportionality between the aerosol mass and the AOT [Koren et al., 2006], and yielded an estimate of $26.2 \mathrm{ktons}\left(26.2 \times 10^{9} \mathrm{~g}\right)$. The third estimate is derived from the backscattering returns of the CALIPSO satellite, which passed over the leading edge of the dust plume, $\sim 400 \mathrm{~km}$ from the coast (see Figure S9). For the limited region of the dust plume examined by both satellites, the CALIPSO results are similar to those from method two, above (see auxiliary material).

[11] There are a number of uncertainties that we cannot fully resolve in scaling from the dust mass estimate from this "snapshot" to estimating the total dust deposition during the entire November, 2006 dust storm, which persisted intermittently for eighteen days (see Figure S7; see http://woodshole.er.usgs.gov/staffpages/jcrusius/research/ CopperRiverDustNov2006B.htm). However, we note that during this two-week storm there were several days with large dust plumes. Hence, we estimate conservatively that the entire amount of dust deposited over the GoA during the event was at least three times the amount inferred from the 

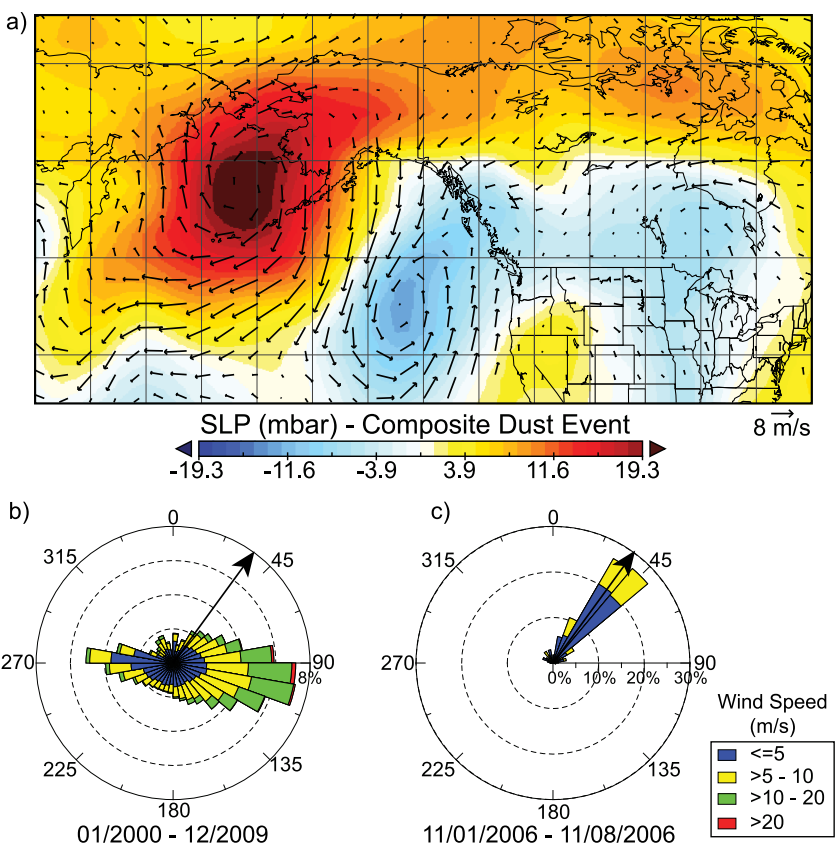

Figure 3. (a) NCEP-NCAP reanalysis [Kalnay et al., 1996] for the GoA region, showing the average of surface wind and sea level pressure daily anomalies for November 5, 2005, November 1 and 6, 2006, and October 29, 2009, when significant dust plumes were evident; (b) wind rose diagram illustrating relative frequency distribution of hourly Middleton Island wind speed and direction from 2000 to 2009; (c) same as Figure 3b, but for hourly measurements spanning November 1-8, 2006 when significant dust was observed. Arrow bearing in Figures $3 \mathrm{~b}$ and $3 \mathrm{c}$ points to Copper River delta.

6 November, 2006 image (see auxiliary material). Thus, the total amount of dust deposited on the GoA from the Copper River is estimated to have been at least $30-80$ ktons. The Copper River delivers only $18 \%$ of the freshwater to the GoA, while $50 \%$ of freshwater discharge to the Gulf is derived from small coastal watersheds, many of which drain glacierized landscapes [Wang et al., 2004]. Hence, there is potential for many smaller sources of dust from along this Alaskan coastline, derived by similar mechanisms, as seen on 17 November, 2010 (Figure 1c), and other occasions. For this reason, we estimate the total dust deposition on the GoA from all of the glacier-dominated GoA watersheds during November, 2006 to have been at least 60-160 ktons.

[12] From our estimate of the mass of dust deposited on the ocean during November, 2006, we can estimate the flux of soluble iron. The dust total iron content is $5 \%$ by weight [Schroth et al., 2009]. However, the proportion of the iron released into solution in surface waters is uncertain, as estimates range from 0.1-90\% [de Baar and de Jong, 2001; Wu et al., 2007]. We assume that $2-5 \%$ of the iron dissolves, a reasonable range for glacial flour [Schroth et al., 2009] (see above). We thus estimate that between 30-200 metric tons of soluble iron were released to surface waters from the Copper River valley-derived dust. Assuming at least twice as much dust was deposited from all of the glacierized riverbed sources, the soluble Fe load to the entire GoA from this dust event would have been at least 60-400 metric tons.
[13] It is worth noting that the dust events occur primarily in the autumn, when light levels are low. Further work will be needed to assess whether these dust events trigger autumn blooms or whether the iron remains unused until light levels increase in the spring. If it is the latter, the iron might be fairly well dispersed prior to biological uptake, leading to a modest stimulation of primary production over a large area, rather than a large increase where the dust is deposited. Dust transport in the late winter (e.g., March, 2003; Figure S1), would occur just as increased light can initiate phytoplankton blooms, and as such, warrants further investigation.

\subsection{Comparison of Fe Sources}

[14] We compare the Fe flux from dust to estimates from other sources because dust is only one important source of $\mathrm{Fe}$ to the GoA. Eddies of coastal origin are thought to transport significant $\mathrm{Fe}$ as well. Haida eddies originate on the continental shelf near the Haida Gwai islands and transport shelf-derived iron westward [Johnson et al., 2005]. We have estimated $\mathrm{Fe}$ transport to GoA surface waters from Haida eddies from the Johnson et al. estimate of "labile" Fe in the top $100 \mathrm{~m}$, together with their estimate of the vertical flux. This yields an estimate of "labile" iron transported in these eddies to the open GoA surface waters of $\sim 170$ metric tons/year (see auxiliary material). The northern extent of these eddies is several hundred $\mathrm{km} \mathrm{SE}$ of the southerly extent of the visible dust plumes. However, there are eddies that propagate from the Sitka, Kenai and Yakutat areas that transport Fe to the northern GoA [Ladd et al., 2009; Rovegno et al., 2009]. If we assume two eddies per year from each of these sites, and that each transports a comparable amount of $\mathrm{Fe}$ to that estimated from the Haida eddies, the total "labile" Fe transport to GoA surface waters from eddies would be roughly $\sim 700$ metric tons/year.

[15] There are other important sources of iron to the ocean, as well. Icebergs contain large quantities of sediment-hosted iron and are often transported to Fe-limited waters before melting [Raiswell et al., 2006]. While icebergs may indeed be important in the Southern Ocean, they are likely not very important in the GoA because there is no large ice sheet and no winter sea ice [e.g., Higgins and Cassano, 2009]. Combustion is another important $\mathrm{Fe}$ source in some locations, although Luo et al. [2008] concluded that this is not an important flux to the open ocean.

\subsection{Other Dust Observations From High Latitudes}

[16] There are very few observations of dust deposition from the GoA region. One recent inference from snowpack and ice cores from nearby Mt. Logan $\left(60.6^{\circ} \mathrm{N}, 140.5^{\circ} \mathrm{W}\right)$ has documented aerosol inputs from Asia, based on analyses of $\mathrm{Nd}, \mathrm{Sr}$ and $\mathrm{Pb}$ isotopes [Zdanowicz et al., 2006]. These records were collected $\sim 100 \mathrm{~km}$ north of Yakutat Bay (Figure 1b), but at an elevation of 2000-5000 m. We suggest that the origin of these aerosols may well be Asian dust, but that these sites are failing to intercept the low-level coastal dust plumes transported to the GoA (Figure 1).

[17] The limited observations at this and other high-latitude sites beg the question of whether dust transport may have received insufficient attention at high latitude sites, where melting of glaciers and ice sheets might yield fine particles that lead to dust. Offshore transport of glacial dust has been observed near Iceland (J. Prospero, personal communica- 
tion, 2010), but there are few direct observations. The Southern ocean is the only high-latitude high-nutrient lowchlorophyll region outside of the subarctic North Pacific. Patagonia is an important dust source [e.g., Johnson et al., 2010] but is understudied with respect to Fe supply.

\subsection{Is Climate Change Causing Increased Aerosol Fe Transport?}

[18] The observation of large dust plumes emanating from the Copper River valley in recent years, together with observations that glaciers in this region are retreating rapidly [Luthcke et al., 2008] cause us to wonder whether dust transport is increasing in high-latitude locations in response to climate change. The dearth of observations precludes answering this for the GoA region. However, dust storms were reported at similar times of year in 1899, 1910 and 1911 [Tarr and Martin, 1913], which is not unexpected, because seasonal glacier melting followed by decreases in river levels would have exposed extensive dust source material even then. It remains important to examine whether dust fluxes are increasing in high-latitude locations in response to glacial recession and climate change, and what the impact might be on marine ecosystems.

\section{Conclusions}

[19] Substantial glacial flour-derived dust is transported annually, and perhaps more frequently, from sediment deposits of the Copper River (AK), and other nearby rivers, into the GoA. Dust is often transported several hundred kilometers beyond the continental shelf, into waters where primary productivity is Fe-limited. These events occur most commonly during autumn when strong winds blow over riverbed sediments from glacierized river valleys, as water levels decrease. We estimate at least 60-160 ktons of dust were deposited on the GoA during a 2006 event. Based on the mineralogy and Fe speciation of this dust, we estimate that at least 60-400 tons of soluble Fe were released into surface waters, which is comparable to that transported to surface waters annually by eddies of coastal origin. Given that glaciers are retreating in the coastal GoA region and in other locations, it is important to examine whether fluxes of dust are increasing from glacierized landscapes to the ocean, and to assess the impact of associated $\mathrm{Fe}$ on marine ecosystems.

[20] Acknowledgments. We appreciate support from the USGS CMGP, NCCWSC, the Mendenhall postdoc program, the Woods Hole PEP intern program, and from NASA-IDS. We thank D. Eberl (USGS) for quantitative XRD data. We also thank J. Bargar and J. Rogers at Stanford Synchrotron Radiation Light Source, run on behalf of the DOE and E. Sholkovitz, D. Muhs, and two others for reviews.

[21] The Editor thanks two anonymous reviewers.

\section{References}

Boyd, P. W., et al. (2004), The decline and fate of an iron-induced subarctic phytoplankton bloom, Nature, 428(6982), 549-553, doi:10.1038/ nature02437.

Brabets, T. P. (1997), Geomorphology of the Lower Copper River, Alaska, U.S. Geol. Surv. Prof. Pap., 1581.

Conkright, M. E., et al. (1994), World Ocean Atlas 1994, vol. 1, Nutrients, NOAA Atlas NESDIS, vol. 1, 162 pp., NOAA, Silver Spring, Md.

Cwiertny, D. M., J. Baltrusaitis, G. J. Hunter, A. Laskin, M. M. Scherer, and V. H. Grassian (2008), Characterization and acid-mobilization study of iron-containing mineral dust source materials, J. Geophys. Res., 113, D05202, doi:10.1029/2007JD009332. de Baar, H. J. W., and J. T. M. de Jong (2001), Distributions, Sources and Sinks of Iron in Seawater, in The Biogeochemistry of Iron in Seawater, edited by D. R. Turner and K. A. Hunter, pp. 123-254, IUPAC, New York.

Higgins, M. E., and J. J. Cassano (2009), Impacts of reduced sea ice on winter Arctic atmospheric circulation, precipitation, and temperature, J. Geophys. Res., 114, D16107, doi:10.1029/2009JD011884.

Johnson, M. S., N. Meskhidze, F. Solmon, S. Gassó, P. Y. Chuang, D. M. Gaiero, R. M. Yantosca, S. Wu, Y. Wang, and C. Carouge (2010), Modeling dust and soluble iron deposition to the South Atlantic Ocean, J. Geophys. Res., 115, D15202, doi:10.1029/2009JD013311.

Johnson, W. K., et al. (2005), Iron transport by mesoscale Haida eddies in the Gulf of Alaska, Deep Sea Res., Part II, 52(7-8), 933-953, doi:10.1016/j. dsr2.2004.08.017.

Journet, E., K. V. Desboeufs, S. Caquineau, and J.-L. Colin (2008), Mineralogy as a critical factor of dust iron solubility, Geophys. Res. Lett., 35, L07805, doi:10.1029/2007GL031589.

Kalnay, E., et al. (1996), The NCEP/NCAR 40-year re-analysis project, Bull. Am. Meteorol. Soc., 77, 437-471, doi:10.1175/1520-0477(1996) 077<0437:TNYRP $>2.0 . \mathrm{CO} ; 2$.

Koren, I., et al. (2006), The Bodele depression: A single spot in the Sahara that provides most of the mineral dust to the Amazon forest, Environ. Res. Lett., 1, 014005, doi:10.1088/1748-9326/1/1/014005.

Ladd, C., et al. (2009), A synoptic survey of young mesoscale eddies in the eastern Gulf of Alaska, Deep Sea Res., Part II, 56(24), 2460-2473, doi:10.1016/j.dsr2.2009.02.007.

Lippiatt, S. M., et al. (2010), The distribution of reactive iron in northern Gulf of Alaska coastal waters, Mar. Chem., 121(1-4), 187-199, doi:10.1016/j.marchem.2010.04.007.

Luo, C., N. Mahowald, T. Bond, P. Y. Chuang, P. Artaxo, R. Siefert, Y. Chen, and J. Schauer (2008), Combustion iron distribution and deposition, Global Biogeochem. Cycles, 22, GB1012, doi:10.1029/ $2007 \mathrm{~GB} 002964$.

Luthcke, S. B., et al. (2008), Recent glacier mass changes in the Gulf of Alaska region from GRACE mascon solutions, J. Glaciol., 54(188), 767-777, doi:10.3189/002214308787779933.

Mahowald, N. M., et al. (2009), Atmospheric iron deposition: Global distribution, variability, and human perturbations, Annu. Rev. Mar. Sci., 1, 245-278, doi:10.1146/annurev.marine.010908.163727.

Raiswell, R., et al. (2006), Contributions from glacially derived sediment to the global iron (oxyhydr)oxide cycle: Implications for iron delivery to the oceans, Geochim. Cosmochim. Acta, 70(11), 2765-2780, doi:10.1016/j.gca.2005.12.027.

Remer, L. A., et al. (2005), The MODIS aerosol algorithm, products and validation, J. Atmos. Sci., 62, 947-973, doi:10.1175/JAS3385.1.

Rovegno, P. S., C. A. Edwards, and K. W. Bruland (2009), Observations of a Kenai eddy and a Sitka eddy in the northern Gulf of Alaska, J. Geophys. Res., 114, C11012, doi:10.1029/2009JC005451.

Schroth, A. W., et al. (2009), Iron solubility driven by speciation in dust sources to the ocean, Nat. Geosci., 2(5), 337-340, doi:10.1038/ngeo501.

Tarr, R. S., and L. Martin (1913), Glacier deposits of the continental type in Alaska, Geology, 21, 289-300, doi:10.1086/622063.

Wang, J., M. Jin, D. L. Musgrave, and M. Ikeda (2004), A hydrological digital elevation model for freshwater discharge into the Gulf of Alaska, J. Geophys. Res., 109, C07009, doi:10.1029/2002JC001430.

Wu, J., R. Rember, and C. Cahill (2007), Dissolution of aerosol iron in the surface waters of the North Pacific and North Atlantic oceans as determined by a semicontinuous flow-through reactor method, Global Biogeochem. Cycles, 21, GB4010, doi:10.1029/2006GB002851.

Wu, J., A. Aguilar-Islas, R. Rember, T. Weingartner, S. Danielson, and T. Whitledge (2009), Size-fractionated iron distribution on the northern Gulf of Alaska, Geophys. Res. Lett., 36, L11606, doi:10.1029/ 2009GL038304.

Zdanowicz, C., et al. (2006), Asian dustfall in the St. Elias Mountains, Yukon, Canada, Geochim. Cosmochim. Acta, 70, 3493-3507, doi:10.1016/j.gca.2006.05.005.

J. Crusius and A. W. Schroth, Woods Hole Coastal and Marine Science Center, U.S. Geological Survey, 384 Woods Hole Rd., Woods Hole, MA 02543, USA. (jcrusius@usgs.gov)

S. Gassó, Goddard Earth Sciences and Technology Center, University of Maryland Baltimore County, 5523 Research Park Dr., Ste. 320, Baltimore, MD 21228, USA.

M. Gatica, School of Earth and Environmental Sciences, Queens College, City University of New York, 65-30 Kissena Blvd., Flushing, NY 11367, USA.

R. C. Levy, Science Systems and Applications, Inc., 10210 Greenbelt Rd., Ste. 600, Lanham, MD 20706, USA.

C. M. Moy, Geology Department, University of Otago, PO Box 56, Dunedin 9054, New Zealand. 